\title{
MPAN - Does Upper and Lower Motor Neuron Lesion Correspond with the C19orf12 Phenotype? - Case Report
}

\author{
Elżbieła Szczygieł - Piluł', Agata Stenwak² and Monika Rudzińska - Bar³
}

Department of Neurology and Neurorehabilitation, John Paul's II Hospital, Cracow, Poland.

Department of Neurology, Jagiellonian University in Cracow, Poland.

Department of Neurology, Medical University of Silesia, Katowice, Poland.
"Correspondence:

Elżbieta Szczygieł - Pilut, Department of Neurology and Neurorehabilitation, John Paul's II Hospital, Cracow, Poland, E-mail: eszczygiel@vp.pl.

Received: 14 August 2018; Accepted: 27 September 2018

Citation: Elżbieta Szczygieł - Pilut, Agata Stenwak, Monika Rudzińska - Bar. MPAN - Does Upper and Lower Motor Neuron Lesion Correspond with the C19orf12 Phenotype? - Case Report. Neurol Res Surg. 2018; 1(1): 1-3.

Keywords

Membrane protein associated neurodegeneration (MPAN), Neurodegeneration with brain iron accumulation, NBIA

\section{Introduction}

Mutations in the C19orf12 gene cause mitochondrial membrane protein associated neurodegeneration (MPAN) is an neurodegeneration with brain iron accumulation (NBIA). We present the adult patient of movement disorders and also features of upper and lower motor neuron lesion.

\section{Case Report}

18 year-old man (WP) with progressive since early childhood gait disturbaces, speech and learning disorders. Patient from the first pregnancy, supported pharmacologically, born with Apgar 8 score, because of fetal malpresentation.

He started walking at the age of 15 months, from this time increasing gait disturbances have been observed (for example tiptoe walking, jousting). He started talking about 2 years of age, from about 6 years of age appeared stuttering and slurred, nasal speech. In the first decade of life, because of the increasing learning disorders, particularly in reading and writing, he became under pedagogical, psychological and neurological care. Family history of this patient was nonspecific for any neurological disease; although in his family unexplained deaths of newborns were observed (mother's 3. siblings).

In years 2010 and 2011 the patient was hospitalized in the University Children's Hospital in Cracow, where MRI examination showed changes in deep brain structures, which suggested pathological iron or copper accumulation. Psychological examination indicated the intellectual capabilities were than average. Level of copper (plasma and urine collection) and iron (plasma) were normal.

Patient was hospitalized in 2012 in the Department of Neurology, Jagiellonian University in Cracow. The patient's neurological symptoms included dysarthria, dysphagia, involuntary movements of face (dystonia) and four limbs (dystonia, choreoathetosis), limb muscle hypotonia, gait with knee hyperextension and foot dropping, bilateral Babinski sign, generalized muscle atrophy, pes cavus. Deep tendon reflexes were normal.

MRI-neuroimaging using gadolinium contrast showed changes with reduced signal on T2-weighted and FLAIR images within the globus pallidus and midbrain substantia nigra, which suggested pathological brain iron accumulation (Pictures 1 and 2).

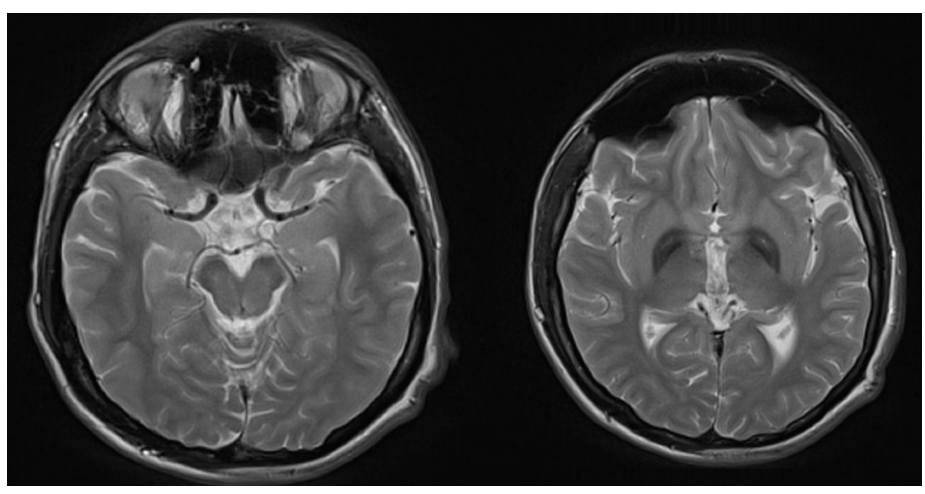

Picture 1: 2012, T2-weighted MR image. Hypointense area in midbrain substantia nigra.

Picture 2: 2012, T2-wieghted MR image, hypointense area in globi pallidi.

The ophthalmologic examination showed blurred vision, optic disc pallor (no optic nerve atrophy) and absence of Kaiser-Fleischer 
ring. Using EMG/ENG, neuropathy was excluded. What pays particular attention, this test revealed chronic neurogenic damage in all tested muscles (right deltoid muscle, first dorsal right interossei musle, extensive right thigh muscle, right tibialis anterior muscle) with features of reinervation and active denervation in all of them. Fasciculations and fibrillations were also observed. This may be the reason of a damage of anterior horn motor cells of the spinal cord at the level of C5-C6, C8-Th1, L3-L4, L5-S1. Neuropsychological examination indicated impaired cognitive functions, emotional lability and mood changes. Electroencephalogram revealed generalized groups of delta waves, which correlated with the patient's cognitive disfunction.

\section{Discussion}

Neurodegeneration with brain iron accumulation presents many common features, such as gait disturbaces, speech and swallowing disfunction, movement disorders, optic nerve atrophy, motor neuropathy and ataxia. However, the patient's examination results were peculiar due to absence of clear optic nerve atrophy and features of peripheral neuropathy. The neurological examination did not reveal ataxia and proprioception or superficial sensory deficits. Thus, in the initial stage of diagnosing, we considered a number of NBIA- related diseases, such as PANK-1, aceruloplasminemia, neuroferritynopathy, early - onset PLAN, MPAN [1-4].

Firstly, our patient was diagnosed by neuropsychologist with progressive cognitive decline, which isn't characteristic for PANK-1 [5-7]. Also, MRI hyperintense area localized bilateral in the globus pallidus, was not described by radiologist as the "eyeof-the-tiger" sign, which is pathognomonical for PKAN. These facts were the main reasons why we refused PKAN as the potential diagnosis. Secondly, neurological examination showed no ataxia and sensory disorders, additional studies revealed no cerebral, cerebellar and optic nerve atrophy, that's why we refused also the early onset -PLAN as the correct diagnosis [8]. Our next choice of differential diagnosis was aceruloplasinemia. The marked level of ceruloplasmin, ferritin, iron and copper (both plasma and urine collection) were normal. We did not observe any ataxia, retinal degeneration and features of diabetes mellitus [7].

Because of that, we decided to search for more probable diagnosis, such as neuroferritinopathy (NFP). It is a disorder characterized by neurological deficits (orobuccolingual diskinesias, extrapyramidal signs, ataxia, cognitive decline), due to NFL gene mutation, that causes excess iron and ferritin brain accumulation. Specific for NFP are the MRI T2 hyperintense abnormalities, which are seen in the deep brain structures like globi pallidi, putamen, caudate nucleus, thalamus, dentate nucleus and substantia nigra [7]. In our patient's MRI images these hyperintense areas related only to globi pallidi and substantia nigra and we didn't find these features placed in other locations. Moreover, we did not notice reduction of serum ferritine.

That led us to the next possible disease - MPAN (mitochondrial membrane protein-associated neurodegeneration). Main features of the disease are: progressive cognitive decline with psychiatric syndromes, gait disturbaces, parkinsonism, dystonia, pyramidal signs (spasticity, hyperreflexia, Babinski sign), optic atrophy, motor axonal neuronopathy. As well as in the other subtypes of NBIA - hypoinensity in T2W MRI images are observed [9]. Hartig et al. documented a cohort of 18. patients, all of them presented optic atrophy and only part of them (44\%) motor axonal neuropathy [9]. Despite of these two missing features we decided to verify patient's DNA for C19orf12 mutation, which is responsible for MPAN phenotype. The patient's DNA sample was sequenced in Technische Univerisität In München, Institut Für Humangenetik. The DNA sequence analysis of C19orf12 revealed a homozygous frame shift mutation in exon 3. c.[204_214del];[204_214del], p.[Gly69Argfs*10];[ Gly69Argfs*10]).

\begin{tabular}{|c|c|c|c|c|}
\hline & Patient 1* & Patient $2 *$ & Patient 3* & WP \\
\hline Age of onset & Adolescenece & $<10$ year & $<10$ year & $<10$ year \\
\hline Muscle tonus & $\mathrm{N}$ & $\mathrm{N}$ & $\uparrow$ & $\downarrow$ \\
\hline $\begin{array}{l}\text { Muscle } \\
\text { strength }\end{array}$ & $\downarrow$ & $\downarrow$ & $\downarrow$ & $\downarrow$ \\
\hline $\begin{array}{l}\text { Deep tendon } \\
\text { reflexes }\end{array}$ & $\downarrow$ & $\uparrow$ & $\uparrow \downarrow$ & $\mathrm{N}$ \\
\hline $\begin{array}{c}\text { Babinski } \\
\text { sign/plantar } \\
\text { reflex }\end{array}$ & + & + & + & + \\
\hline Fasciculations & - & - & - & - \\
\hline $\begin{array}{l}\text { Muscle } \\
\text { atrophy }\end{array}$ & + & + & + & + \\
\hline Pes cavus & + & + & + & + \\
\hline $\begin{array}{l}\text { Mental/ } \\
\text { behavior } \\
\text { disorder }\end{array}$ & + & + & + & + \\
\hline $\begin{array}{c}\text { Vision } \\
\text { difficulties }\end{array}$ & - & + & + & + \\
\hline $\begin{array}{l}\text { Movement } \\
\text { disorder }\end{array}$ & - & - & - & + \\
\hline $\begin{array}{c}\text { Speech } \\
\text { difficulties }\end{array}$ & - & - & + & + \\
\hline EMG & $\begin{array}{c}\text { no } \\
\text { spontaneous } \\
\text { activity, high } \\
\text { amplitudes of } \\
\text { motor } \\
\text { unit potential }\end{array}$ & $\begin{array}{c}\text { no } \\
\text { spontaneous } \\
\text { activity, } \\
\text { high } \\
\text { amplitudes } \\
\text { of motor } \\
\text { unit } \\
\text { potential }\end{array}$ & $\begin{array}{c}\text { fibrillations } \\
\text { and } \\
\text { slightly } \\
\text { increased } \\
\text { amplitudes } \\
\text { motor unit } \\
\text { potential }\end{array}$ & $\begin{array}{c}\text { fibrillations, } \\
\text { fasciculations, } \\
\text { chronic } \\
\text { neurogenic } \\
\text { damage in all } \\
\text { tested } \\
\text { muscles with } \\
\text { features of } \\
\text { reinervation } \\
\text { and } \\
\text { active } \\
\text { denervation in } \\
\text { all of them, }\end{array}$ \\
\hline $\begin{array}{l}\text { MRI images of } \\
\text { GP and } \\
\text { midbrain } \\
\text { suggesting } \\
\text { brain } \\
\text { iron } \\
\text { accumulation }\end{array}$ & + & + & + & + \\
\hline
\end{tabular}

* Deschauer et al. J Neurol. 2012 Nov.

In summary, our patient except of movement disorders had also 
features of upper and lower motor neuron lesion. Deschauer et al. documented in 2013, three cases of patients with C19orf12 mutations (p.Gly66del, Gly69Argfs*10) mimicking juvenile amyotrophic lateral sclerosis [1]. Our case is another example of coexistence of C19orf12 mutation with cortico-spinal/ corticobulbar tracts lesion. In comparison, patient WP presented many similarities with cases described by Deschauer, but only our patient had movement disorders like dystonia and choreoatetosis (Table 1). Among these three presented cases, only patient nr 3 had the same deletion. Genetic examination of Patient nr 3 revealed a heterozygous farme shift mutation in exon 3. (Gly69Argfs*10), meanwhile our patient was a homozygote. It may be the premise, that phenotype of MPAN may vary according to the type of mutation or zygosity. Features of upper and lower motor neuron lesion can be a more frequent symptom of this new subtype of NBIA, but not necessarily.

\section{Conclusion}

Previous publications about MPAN mimicking juvenile ALS documented in a few cases. Due to the fact, that this is a relatively new disease entity, observation of more patients with documented C19orf12 mutation may allow to complement the MPAN's phenotype of new features.

\section{References}

1. Deschauer M, Gaul C, Behrmann C, et al. C19orf12 mutations in neurodegeneration with brain iron accumulation mimicking juvenile amyotrophic lateral sclerosis. J Neurol. 2012; 259: 2434-2439.

2. Keogh MJ, Chinnery PF. Current concepts and controversies in neurodegeneration with brain iron accumulation. Semin Pediatr Neurol. 2012; 19: 51-56.

3. Hogarth P, Gregory A, Kruer MC, et al. NewNBIAsubtype: Genetic, clinical, pathologic, and radiographic features of MPAN. Neurology. 2013; 80: 268-275.

4. Ohta E, Takiyama Y. MRI findings in neuroferritinopathy. Neurol Res Int. 2012; 197438.

5. Clement F, Devos D, Moreau C, et al. Neurodegeneration with brain iron accumulation: clinical, radiographic and genetic heterogeneity and corresponding therapeutic options. ActaNeurol Belg. 2007; 107: 26-31.

6. Hartig MB, Prokisch $\mathrm{H}$, Meitinger $\mathrm{T}$, et al. Pantothenate kinase-associated neurodegeneration. Curr Drug Targets. 2012; 13: 1182-1189.

7. Patil PV, Manakshe G, Mahajan DP, et al. Neurodegeneration with brain iron accumulation--late onset slowly progressive variant. J Assoc Physicians India. 2011; 59: 319-321.

8. Schneider SA, Bhatia KP. Syndromes of neurodegeneration with brain iron accumulation. Semin Pediatr Neurol. 2012; 19: 57-66.

9. Hartig MB, Iuso A, Haack T, et al. Absence of an orphan mitochondrial protein, c19orf12, causes a distinct clinical subtype of neurodegeneration with brain iron accumulation. Am J Hum Genet. 2011; 89: 543-550. 